\title{
A study on effect of phototherapy on platelet count in neonates with unconjugated hyperbilirubinemia: a hospital based prospective observational study
}

\author{
Santi Kumar Sarkar ${ }^{1}$, Biswajit Biswas $^{2}$, Sumanta Laha ${ }^{3}$, Nirban Sarkar ${ }^{4}$, Monojit Mondal $^{5}$, \\ Jasni Angel ${ }^{6}$, Veeresh ${ }^{7}$, Kumar Abhisek ${ }^{8}$, Vinay Kumar ${ }^{9}$, Arkaprava Acharya ${ }^{10}$, \\ Priyanka Biswas ${ }^{11}$, Subhamoy Mal ${ }^{12}$, Debahsis Ghosh ${ }^{13}$, Trishita Mukherjee ${ }^{14}$ \\ 1,4,5,6,7,8, 10,13,14Senior Resident, 2,3 Associate Professor, ${ }^{11,12}$ Junior Resident, Department of Pediatric Medicine, Burdwan \\ Medical College, Burdwan, West Bengal, India.
}

Background: Thrombocytopenia as a side effect of phototherapy has not been mentioned in standard literature and textbooks. Though there are few studies in this regard, but results are conflicting. Aims and Objective: Hence, the present study is undertaken to find out whether any significant change in platelet count occurs following phototherapy, and if there be any, to see whether the changes are transient or not. Materials and Methods: This prospective and observational study was carried out over a period of one and half years ( $1^{\text {st }}$ March 2019 to $31^{\text {st }}$ August 2020) on 190 new-borns admitted with idiopathic unconjugated hyperbilirubinemia needing phototherapy through consecutive enrolment. Serum bilirubin (total, conjugated and unconjugated) and platelet count were done before initiation and just after completion of phototherapy, and seven days after completion of phototherapy. Appropriate statistical tests were used to make statistical comparisons with a p-value of $<0.05$ taken as significant. Results: Among 190 neonates, 108(56.8\%) were male and $82(43.2 \%)$ were female; 90(47.4\%) were preterm and $100(52.6 \%)$ were term. Mean birth weight was (2.4725 \pm 0.4782$) \mathrm{kg}$. Mean gestational age was (36.4316 \pm 2.4802$)$ weeks. Mean haemoglobin level was $(17.3816 \pm 1.0784) \mathrm{gm} / \mathrm{dl}$. Mean age at presentation was $(4.5737 \pm 1.5811)$ days. Mean total serum bilirubin (TSB) before initiation, after completion, and 7 days after completion of phototherapy were $(17.8595 \pm 3.7034) \mathrm{mg} / \mathrm{dl}$, $(8.1726 \pm 2.2586) \mathrm{mg} / \mathrm{dl}$ and $(5.7279 \pm 1.5918) \mathrm{mg} / \mathrm{dl}$ respectively. The mean duration of phototherapy required was $(48.1895 \pm 13.6054)$ hours. Mean platelet count before initiation and just after completion of phototherapy were $(2,49,321.0526 \pm 89,460.2101) / \mu \mathrm{L}$ and $(2,22,436.8421 \pm 88,538.7173) / \mu \mathrm{L}$ respectively. Mean platelet count 7 days after completion of phototherapy was $(2,46,210.5263 \pm 87,442.3038) / \mu \mathrm{L}$. Decrease in platelet count just after completion of phototherapy was statistically significant. Fifty-nine (31.1\%) out of 190 neonates developed mild thrombocytopenia (100000- $<150000 / \mu \mathrm{L})$ just after completion of phototherapy, but none developed moderate or severe thrombocytopenia. None having thrombocytopenia manifested with clinical bleed. Platelet count raised near to pre-phototherapy level 7 days after completion of phototherapy. Fall in platelet count was found to have a positive association with increased duration of phototherapy and lower gestational age $(p<0.0001)$. However, there was no statistically significant association $(p>0.05)$ between reduction in platelet count with gender. Conclusions: Though the incidence of thrombocytopenia following phototherapy was significant, but it was mostly mild and transient, and clinically insignificant. There was significant association between decrease of platelet count with duration of phototherapy and lower gestational age.

\section{Access this article online}

Website:

http://nepjol.info/index.php/AJMS DOI: 10.3126/ajms.v12i5.33965

E-ISSN: 2091-0576

P-ISSN: 2467-9100

Copyright (c) 2021 Asian Journal of Medical Sciences

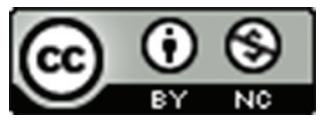

This work is licensed under a Creative Commons Attribution-NonCommercial 4.0 International License.

Key words: Thrombocytopenia; phototherapy; neonatal jaundice 


\section{INTRODUCTION}

Pathological or significant neonatal jaundice due to unconjugated hyperbilirubinemia is one of the most common causes of admission to sick neonatal care unit (SNCU). Phototherapy (PT) is the most common and important modality of treatment in these patients irrespective of the etiology of jaundice. Skin rash, loose stools, hyperthermia, dehydration and electrolyte imbalance are some well-known side effects of this therapy. ${ }^{1-3}$ Thrombocytopenia has not yet been mentioned as an adverse consequence of PT in any of the standard textbooks of pediatric medicine or neonatology. Though few studies have been published on this topic, results are conflicting. So, this study was done to observe the effect of phototherapy on platelet count in neonates with unconjugated hyperbilirubinemia.

\section{MATERIALS AND METHODS}

The prospective observational study was carried out in the sick newborn care unit (SNCU) in the Division of Neonatology under the Department of Pediatric Medicine, Burdwan Medical College and Hospital, West Bengal, India. Total study period was one and half year (1 ${ }^{\text {st }}$ March 2019 to $31^{\text {st }}$ August 2020).

\section{Inclusion criterion}

Apparently healthy neonates having phototherapeutic level unconjugated hyperbilirubinemia decided as per American Academy of Pediatrics (AAP) guideline (for neonates with gestational age of 35 weeks or more $)^{4}$ and Facility Based Newborn Care (FBNC), Ministry of Health and Family Welfare, Government of India guideline (for neonates aged less than 35 weeks); ${ }^{5}$ and a base line platelet count of more than $1,50,000 / \mathrm{dl}$ were included in the study.

\section{Exclusion criteria}

Neonates with conjugated hyperbilirubinemia, ABO and Rh incompatibility, septicemia, birth asphyxia, renal failure, hemangioma, antiplatelet drugs given to mother or baby, congenital anomalies were excluded.

Sample Size was 190, calculated with the formula, $\mathrm{n}=\mathrm{z}^{2} \mathrm{pq} / \mathrm{d}^{2}(\mathrm{z}=$ standard normal variate taken as 1.96 considering 5\% type 1 error and $\mathrm{p}<0.05, \mathrm{p}=$ prevalence/ expected proportion of neonates likely to develop thrombocytopenia after receiving PT which was taken as $50 \%$ or 0.5 as results from previously available studies were conflicting., $\mathrm{q}=1-\mathrm{p}, \mathrm{d}=$ absolute error/precision/ clinically allowable error which was taken as $7.5 \%$ or 0.075 ). Sampling technique employed was consecutive enrollment till sample size was reached. An informed written consent was obtained from every parent of the newborns before enrolling them in the study. Study was approved by Hospital Ethical Committee and Scientific Committee (vide memo no BMC/379/2019).

After initial history taking, clinical examination and laboratory investigations, all babies were put to continuous phototherapy with interruption only during breast feeding. The neonates were followed up daily for monitoring the side effects. Total serum bilirubin (TSB) and platelet count were measured before initiation of phototherapy, just after completion of phototherapy and seven days after completion of phototherapy. Platelet count before initiation of PT was taken as control value for respective neonate. Platelet count $<150,000 / \mathrm{mm}^{3}$ was taken as the definition of thrombocytopenia. Mild, moderate and severe thrombocytopenia were graded when platelet counts were between $(100,000$ to 150,000$) / \mathrm{mm}^{3},(50,000-100,000) / \mathrm{mm}^{3}$ and less than $50,000 / \mathrm{mm}^{3}$ respectively. Platelet count above $4,50,000 / \mathrm{mm}^{3}$ was considered as thrombocytosis.

Other parameters studied were sex, birth weight, gestational age (term and preterm), postnatal age (in days), blood group (of both mother and baby), hemoglobin level, mode of delivery and duration of phototherapy. Serum bilirubin was measured by diazo method using semi-automated clinical chemistry analyzer Chem 7, ERBA, Transasia, India. Platelet count was measured by automated hematology analyzer and was confirmed by microscopy. All data were recorded in a predesigned case sheet.

\section{Statistical methods}

For statistical analysis data were entered into a Microsoft excel spreadsheet and then analyzed by SPSS (version 27.0; SPSS Inc., Chicago, IL, USA) and GraphPad Prism version 5. Data had been summarized as mean and standard deviation for numerical variables and count and percentages for categorical variables. Two-sample t-tests was applied for analyzing the difference in mean involving independent samples or unpaired samples. Paired t-tests, one-way ANOVA and chi-squared tests ( $\chi 2$ test) were also used for data analysis. P-value $<0.05$ was considered for statistically significant.

\section{RESULTS}

A total of 190 neonates were included in the present study. Among them 108(56.8\%) neonates were male and $82(43.2 \%)$ were female; $90(47.4 \%)$ neonates were preterm and $100(52.6 \%)$ were term. One hundred and thirty-nine $(73.2 \%)$ neonates were delivered by vaginal delivery (VD) and $51(26.8 \%)$ neonates were delivered by lower uterine caesarean section (LUCS) (Table. 1). 
Mean birth weight of the neonates was $2.4725 \pm .4782 \mathrm{~kg}$. Mean gestational age was $36.4316 \pm 2.4802$ weeks. The average age of presentation for phototherapy was $4.5737 \pm$ 1.5811 postnatal days (Table. 2). Mean haemoglobin level of the neonates was $17.3816 \pm 1.0784 \mathrm{gm} / \mathrm{dl}$. Mean TSB before initiation of phototherapy, just after completion and 7 days after completion of phototherapy were $17.8595 \pm$ $3.7034 \mathrm{mg} / \mathrm{dl}, 8.1726 \pm 2.2586 \mathrm{mg} / \mathrm{dl}$ and $5.7279 \pm 1.5918$ $\mathrm{mg} / \mathrm{dl}$ respectively. The mean duration of phototherapy required was $48.1895 \pm 13.6054$ hours (Table.2).

In our study, mean platelet count before initiation of phototherapy and just after completion of it were $2,49,321.0526 \pm 89,460.2101 / \mu \mathrm{L}$ and $2,22,436.8421 \pm$ $88,538.7173 / \mu \mathrm{L}$ respectively. Mean platelet count recorded 7 days after completion of PT was 2,46,210.5263 $87,442.3038 / \mu \mathrm{L}$ (Table. 3A).

\begin{tabular}{|c|c|c|c|}
\hline \multicolumn{2}{|c|}{ Demographic parameters } & \multirow{2}{*}{$\begin{array}{c}\text { Frequency } \\
108\end{array}$} & \multirow{2}{*}{$\begin{array}{c}\text { Percentage } \\
56.8\end{array}$} \\
\hline Gender & Male & & \\
\hline & Female & 82 & 43.2 \\
\hline \multirow{4}{*}{$\begin{array}{l}\text { Mode of } \\
\text { delivery } \\
\text { Maturity }\end{array}$} & VD & 139 & 73.2 \\
\hline & LSCS & 51 & 26.8 \\
\hline & Preterm & 90 & 47.4 \\
\hline & Term & 100 & 52.6 \\
\hline
\end{tabular}

In 187 neonates $(98.4 \%$ ), mean platelet count before initiation of phototherapy were in between $1,50,000 / \mu \mathrm{L}$ and $4,50,000 / \mu \mathrm{L}$, and in 3 neonates $(1.6 \%)$ value was $>450000 / \mu \mathrm{L}$ (Table. $3 \mathrm{~B})$. In $59(31.1 \%)$ neonates, platelet count just after completion of phototherapy were in the range of $1,00,000 / \mu \mathrm{L}$ to less than $1,50,000 / \mu \mathrm{L}$ and in $131(68.9 \%)$ neonates' values were in between $1,50,000 / \mu \mathrm{L}$ and $4,50,000 / \mu \mathrm{L}$. Seven days after days of completion of phototherapy, platelet count was in the range of $1,50,000 / \mu \mathrm{L}$ to $4,50,000 / \mu \mathrm{L}$ in $188(98.9 \%)$ neonates; and 2 neonates $(1.1 \%)$ had a count of more than 4,50,000/ $\mu \mathrm{L}$ (Table.3B).

Table. 4A shows actual mean platelet counts in the study population $(n=190)$ before initiation of PT, after completion of different durations of PT required, and the corresponding values 7 days after completion of phototherapy. Figure 1 is the graphical representation of the same data series. Decrease in mean platelet count was found after completion of different durations of phototherapy required, and the results were statistically significant $(\mathrm{p}<0.0001)$. Mean platelet count 7 days after completion of phototherapy almost returned back to prephototherapy levels (Table.4A and Figure.1).

Table. 4B shows the actual fall in platelet counts in the study population $(\mathrm{n}=190)$ in relation to duration of phototherapy

Table 2: Mean, standard deviation, range and median of various parameters $(n=190)$

\begin{tabular}{|c|c|c|c|c|c|}
\hline Attribute & Mean & SD & Minimum & Maximum & Median \\
\hline Birth weight (kg) & 2.4725 & 0.4782 & 1.2500 & 3.4500 & 2.5800 \\
\hline Gestational age(week) & 36.4316 & 2.4802 & 30.0000 & 40.0000 & 37.0000 \\
\hline Haemoglobin $(\mathrm{gm} / \mathrm{dl})$ & 17.3816 & 1.0784 & 15.3000 & 19.3000 & 17.4000 \\
\hline Age of presentation(days) & 4.5737 & 1.5811 & 2.0000 & 8.0000 & 5.0000 \\
\hline TSB before phototherapy(mg/dl) & 17.8595 & 3.7034 & 8.5000 & 23.5000 & 18.7000 \\
\hline TSB after completion of phototherapy & 8.1726 & 2.2586 & 3.5000 & 12.9000 & 8.6000 \\
\hline TSB 7days after phototherapy & 5.7279 & 1.5918 & 3.0000 & 9.2000 & 5.4500 \\
\hline
\end{tabular}

Table 3A: Mean platelet counts and their relation to phototherapy $(n=190)$

\begin{tabular}{lccrr}
\hline Platelet count & Mean & SD & Minimum & Maximum \\
\hline Before initiation of PT & $2,49,321.0526$ & $89,460.2101$ & $1,52,000.0000$ & $4,70,000.0000$ \\
After completion of PT & $2,2,2436.8421$ & $88,538.7173$ & $1,20,000.0000$ & $4,33,000.0000$ \\
7days after completion of PT & $2,46,210.5263$ & $87,442.3038$ & $1,50,000.0000$ & $4,60,000.0000$ \\
\hline
\end{tabular}

Table 3B: Range of platelet counts and their relation to phototherapy $(n=190)$

\begin{tabular}{|c|c|c|c|}
\hline Time of analysis & Platelet count (range) & Frequency & Percent \\
\hline \multirow[t]{3}{*}{ Before initiation of PT } & $150000-450000$ & 187 & 98.4 \\
\hline & $>450000$ & 3 & 1.6 \\
\hline & Total & 190 & 100 \\
\hline \multirow[t]{3}{*}{ Just after completion of PT } & $100000-<150000$ & 59 & 31.1 \\
\hline & $150000-450000$ & 131 & 68.9 \\
\hline & Total & 190 & 100 \\
\hline \multirow[t]{2}{*}{7 days after completion of PT } & $150000-450000$ & 188 & 98.9 \\
\hline & Total & 190 & 100.0 \\
\hline
\end{tabular}


received. Fall in platelet count was positively associated with increasing duration of phototherapy $(\mathrm{p}<0.0001)$.

In the present study, fall in mean platelet count just after completion of phototherapy was more prominent among preterm neonates $(\mathrm{p}<0.0001)$ (Table.5).

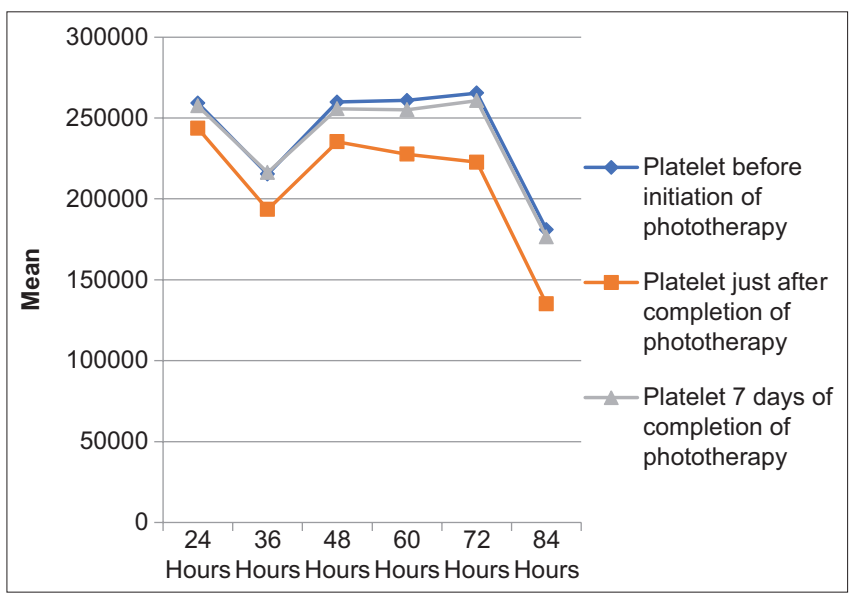

Figure. 1: Relationship between mean platelet count and duration of phototherapy given
Gender and blood group of the neonates, maternal age, parity and mode of delivery did not have any association with fall in platelet count following phototherapy.

\section{DISCUSSION}

It was found that platelet count had decreased significantly just after phototherapy but it was transient because platelet count again raised near to pre phototherapy level seven days after completion of phototherapy. In 187 neonates (98.4\%), mean platelet count before initiation of phototherapy were in between $1,50,000 / \mu \mathrm{L}$ and $4,50,000 / \mu \mathrm{L}$, and in 3 neonates $(1.6 \%)$ value was $>450000 / \mu \mathrm{L}$ (Table. $3 \mathrm{~B})$. In $59(31.1 \%)$ neonates, platelet count just after completion of phototherapy were in the range of $1,00,000 / \mu \mathrm{L}$ to less than $1,50,000 / \mu \mathrm{L}$ and in $131(68.9 \%)$ neonates' values were in between $1,50,000 / \mu \mathrm{L}$ and $4,50,000 / \mu \mathrm{L}$. Seven days after days of completion of phototherapy, platelet count was in the range of $1,50,000 / \mu \mathrm{L}$ to $4,50,000 / \mu \mathrm{L}$ in 188(98.9\%) neonates; and 2 neonates $(1.1 \%)$ had a count of more than 4,50,000/ $\mu \mathrm{L}$ (Table.3B). Among 190 neonates under our study, 59(31.1\%) neonates developed

\section{Table 4A: Mean platelet count and their relation to duration of phototherapy required $(n=190)$}

\begin{tabular}{|c|c|c|c|c|c|c|c|}
\hline \multirow{2}{*}{$\begin{array}{l}\text { Duration of } \\
\text { phototherapy } \\
\text { required }\end{array}$} & \multicolumn{2}{|c|}{$\begin{array}{l}\text { Platelet count before initiation } \\
\text { of PT }\end{array}$} & \multicolumn{2}{|c|}{$\begin{array}{l}\text { Platelet count just after } \\
\text { completion of PT }\end{array}$} & \multicolumn{2}{|c|}{$\begin{array}{l}\text { Platelet count } 7 \text { days after } \\
\text { completion of PT }\end{array}$} & \multirow[t]{2}{*}{ p-value } \\
\hline & Mean & SD & Mean & SD & Mean & SD & \\
\hline 24 Hours & $2,59,222.2222$ & $83,383.2792$ & $2,43,666.6667$ & $83,637.8749$ & $2,57,500.0000$ & $84,048.4804$ & 0.0320 \\
\hline 36 Hours & $2,15,272.7273$ & $57,137.2740$ & $1,93,409.0909$ & $57,988.0975$ & $2,16,318.1818$ & $54,346.7646$ & 0.0450 \\
\hline 48 Hours & $2,59,800.0000$ & $96,020.8636$ & $2,35,246.1538$ & $95,480.5332$ & $2,55,723.0769$ & $94,712.3124$ & 0.0120 \\
\hline 60 Hours & $2,60,822.2222$ & $88,233.7518$ & $2,27,644.4444$ & $88,196.6180$ & $2,55,111.1111$ & $86,529.0866$ & $<0.0001$ \\
\hline 72 Hours & $2,65,437.5000$ & $1,27,024.9155$ & $2,22,625.0000$ & $1,21,104.8444$ & $2,60,750.0000$ & $12,3913.6796$ & $<0.0001$ \\
\hline 84 Hours & $1,81,000.0000$ & 0.0000 & $1,35,000.0000$ & 0.0000 & $1,76,500.0000$ & 2,121.3203 & $<0.0001$ \\
\hline$p$-value & \multicolumn{2}{|c|}{0.0754} & \multicolumn{2}{|c|}{0.0981} & \multicolumn{2}{|c|}{0.1344} & \\
\hline
\end{tabular}

Table 4B: Mean fall in platelet count and their relation to duration of phototherapy needed $(n=190)$

\begin{tabular}{lcccccc}
\hline $\begin{array}{l}\text { Duration of } \\
\text { phototherapy required }\end{array}$ & $\begin{array}{c}\text { Number of } \\
\text { neonates }\end{array}$ & Mean & SD & Minimum & Maximum & Median \\
\hline 24 Hours & 18 & 15555.5556 & 3311.6945 & 7000.0000 & 21000.0000 & 16000.0000 \\
36 Hours & 44 & 21863.6364 & 4348.7015 & 10000.0000 & 32000.0000 & 22000.0000 \\
48 Hours & 65 & 24553.8462 & 12187.3792 & 2000.0000 & 110000.0000 & 24000.0000 \\
60 Hours & 45 & 33177.7778 & 4711.1516 & 21000.0000 & 42000.0000 & 34000.0000 \\
72 Hours & 16 & 42812.5000 & 24752.6935 & 32000.0000 & 135000.0000 & 37500.0000 \\
84 Hours & 2 & 46000.0000 & .0000 & 46000.0000 & 46000.0000 & 46000.0000 \\
\hline
\end{tabular}

\section{Table 5: Relationship of thrombocytopenia following phototherapy with gestational age}

\begin{tabular}{llccccc}
\hline Platelet count & Maturity & Mean & SD & Minimum & Maximum & Median \\
\hline Before phototherapy & Preterm & 215344.4444 & 74994.2561 & 152000.0000 & 460000.0000 & 181500.0000 \\
& Term & 279900.0000 & 90712.0541 & 160000.0000 & 470000.0000 & 275000.0000 \\
After completion of & Preterm & 189633.3333 & 73805.1565 & 120000.0000 & 433000.0000 & 156500.0000 \\
phototherapy & Term & 251960.0000 & 90608.5955 & 121000.0000 & 429000.0000 & 243500.0000 \\
7days after completion & Preterm & 213866.6667 & 73326.7583 & 150000.0000 & 457000.0000 & 180000.0000 \\
of phototherapy & Term & 275320.0000 & 89199.5697 & 156000.0000 & 460000.0000 & 269000.0000 \\
\hline
\end{tabular}


mild thrombocytopenia $(100000-<150000 / \mu \mathrm{L})$ just after phototherapy but no bleeding manifestation was there. Khera $\mathrm{S}$ et $\mathrm{al}^{6}$ reported in their study that $35(35 \%)$ neonates among a total study population of $100 \mathrm{had}$ thrombocytopenia and majority of them (74\%) had mild thrombocytopenia, and thrombocytopenia was transient. Bhargava $\mathrm{O}$ et $\mathrm{al}^{7}$ observed that majority of the neonates had mild (58.2\%) and moderate (20.8\%) thrombocytopenia during the first 48 hours of phototherapy, usually was not associated with clinical bleed, and thrombocytopenia was transient in nature. Majid Vafaie et al ${ }^{8}$ found in their study that the mean platelet counts before initiation of phototherapy, 24 hours thereafter, at the end of phototherapy, and 48 hours after completion of phototherapy were $2,98,170 / \mu \mathrm{L}, 2,88,540 / \mu \mathrm{L}, 2,82,620 / \mu \mathrm{L}$ and $2,66,310 / \mu \mathrm{L}$ respectively which were statistically significant during time. Results of these studies ${ }^{6-8}$ showed that phototherapy led to a significant reduction in platelet count in new-borns receiving phototherapy but changes were mostly transient and usually did not lead to clinical bleed.

Sajid A et al $^{9}$ studied with 150 new-borns with a mean age of $(3.95 \pm 1.71)$ days having unconjugated hyperbilirubinemia. After 24 hours of phototherapy, about $8.1 \%$ of the patients were having severe thrombocytopenia (platelet count $<50,000 / \mu \mathrm{L}$ ); this percentage rose to $18.4 \%$ after 48 hours and $33.3 \%$ after 72 hours of phototherapy. None of the patients developed clinical manifestation of bleeding. The number of patients with normal platelet count $(1,50,000 / \mu \mathrm{L}$ to $4,00,000 / \mu \mathrm{L})$ after 24 hours of continuous phototherapy was $50 \%$, gradually reducing to $38 \%$ after 48 hours and only $33 \%$ after 72 hours of completion of phototherapy ( $\mathrm{p}$ value $<0.05$ ). Khera $\mathrm{S}$ et $\mathrm{al}^{6}$ and Majid Vafaie et $\mathrm{al}^{8}$ also noticed that the degree and incidence of thrombocytopenia increased with increasing duration of phototherapy received. In the present study also differences in mean platelet counts before and just after phototherapy with different durations of phototherapy were statistically significant $(p<0.0001)$. Differences were more marked when duration of PT was longer (Table 4A $\&$ Table 4B). Several other researchers ${ }^{10-13}$ also had similar experience like us.

In the present study, mean birth weight of the study

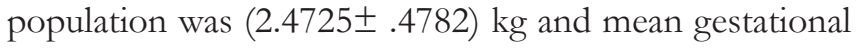
age was (36.4316 \pm 2.4802$)$ weeks. Ninety $(47.4 \%)$ neonates were preterm and $100(52.6 \%)$ were full-term. Mean platelet counts before initiation of PT was lower among preterm babies in our study. Corresponding values were also found to be on a lower side just after completion of PT, and 7 days after completion of PT $(\mathrm{p}<0.0001)$. This finding tallied with the results obtained in studies conducted by Khera $S$ et al ${ }^{6}$ Sajid A et al, ${ }^{9}$ Kannar V et al ${ }^{10}$ and Sonawane P et al. ${ }^{11}$
Though most of the published studies found thrombocytopenia in association with phototherapy, there are few articles which depicted completely different and interesting findings. Ahmadpour KM et al ${ }^{14}$ showed that phototherapy resulted in rise of platelet count but had no significant effect on the WBC and reticulocyte counts. Monsef $\mathrm{A}$ et $\mathrm{al}^{15}$ and Sakha $\mathrm{K}$ et a ${ }^{16}$ also showed increase in platelet count in their study. Modanlou HD et $\mathrm{a}^{17}$ observed that none of the infants who received phototherapy developed thrombocytopenia. Abdul Tawab CN et al ${ }^{18}$ found statistically significant change in the platelet count amongst term new-borns but not in preterm ones after PT.

The drop in platelet counts following PT may be due to the photochemical reaction in the vascular bed and direct platelet injury by the ultraviolet light of phototherapy leading to reduction in platelet life span and an increase in platelet turnover. ${ }^{8-16}$ Thrombocytopenia is expected to be more marked when bone marrow compensation is inadequate, as in the case of preterm neonates.

\section{Limitations of the study}

The notable short comings of this study were: this study was done in a single tertiary care centre thereby limiting the scope for generalisation of the results, and it was conducted predominantly on Bengali population and thus, studies need to be done in other ethnic groups as well for validation of results.

\section{CONCLUSIONS}

Phototherapy can be a cause of decrease in platelet count in neonates receiving PT for unconjugated hyperbilirubinemia. In our study, thrombocytopenia was more prominent with increasing duration of PT and in preterm new-borns. Though the fall in platelet counts were statistically significant, it did not affect the newborns clinically. Moreover, changes were mostly transient, as in most of the cases platelet values retuned back to the pre-treatment level 7 days after completion of PT. We would therefore like to emphasise that clinicians need to be aware of this association so that unnecessary elaborate work ups can be avoided and consequent psychological stress on family members and treating physicians can be minimised.

\section{ACKNOWLEDGEMENT}

The authors are immensely thankful to the Department of Pediatric Medicine for generous support and encouragement towards successful accomplishment of this study. 


\section{REFERENCES}

1. Singh M. Jaundice, Care of the Newborn. Revised 8th ed. New Delhi: CBS Publishers \& Distributors, 2017; 18: 324-349.

2. Gregory MLP, Martin CR and Cloherty JP. Neonatal Hyperbilirubinemia. In: Cloherty JP, Eichenwald EC, Hansen AR, Stark AR (eds.) Manual of neonatal care. 7th ed. Philadelphia: Lippincott Willams and Wilkins. 2012:304-339.

3. Agarwal R, Deorari A and Paul VK. Jaundice, AllMS Protocol in Neonatology.1st ed. New Delhi: CBS Publishers \& Distributors,2015;10:123-137.

4. American Academy of Pediatrics, Subcommittee on Hyperbilirubinemia. Management of hyperbilirubinemia in the newborn infant 35 or more weeks of gestation. Pediatrics. 2004; 114:297-316.

https://doi.org/10.1542/peds.114.1.297

5. Facility Based Newborn Care. Training Module for Doctors and Nurses. Ministry of Health and Family Welfare Government of India. Neonatal Jaundice.2014; 12: 73-78.

6. Khera S and Gupta R. Incidence of thrombocytopenia following phototherapy in hyperbilirubinemic neonates. Medical Journal Armed Forces India. 2011 Oct 1;67(4):329-332.

https://doi.org/10.1016/S0377-1237(11)60078-6

7. Bhargava O, Sutrakar SK, Ghanghoria $P$ and Verma A. Incidence of thrombocytopenia in hyperbilirubinemic neonates following phototherapy. Asian Journal of Research in Chemistry. 2015;8(4):221-30.

https://doi.org/10.5958/0974-4150.2015.00039.5

8. Vafaie M. Incidence of thrombocytopenia following phototherapy in hyperbilirubinemic neonates in Ardabil City. International Journal of Contemporary Pediatrics. 2018;5(6):2274-2277. https://doi.org/10.18203/2349-3291.ijcp20184295

9. Sajid A, Mahmood T, Riaz S and Nabi SG. Phototherapy in Hyperbilirubinemic Neonates; Does it Affect Platelet Count? Annals of King Edward Medical University. 2016;22(3). https://doi.org/10.21649/akemu.v22i3.1405
10. Kannar V, Deepthi A,Harendra Kumar ML, Junjegowda K and Mariyappa N. Effect of gestational age, prematurity and birth asphyxia on platelet indices in neonates. Journal of clinical neonatology. 2014;3(3):144 -147.

https://doi.org/10.4103/2249-4847.140399

11. Sonawane P, Bhaisara B and Bhatawdekar A. Effect of Conventional Phototherapy on platelet count in full term and Preterm Neonates with Indirect Hyperbilirubinemia-A Prospective Cohort Study. JMSCR. 2018(6): 959-966. https://doi.org/10.18535/jmscr/v6i3.160

12. Pishva $\mathrm{N}$ and Pishva $\mathrm{H}$. Incidence of thrombocytopenia in hyperbilirubinemic neonates during phototherapy. Acta Medica Iranica. 2000; 38 (1):7-9.

13. Venaktamurthy M, Balaji MD and Reddy KT. A study on effect of phototherapy on platelet count in neonates with neonatal hyperbilirubinemia in a tertiary care rural hospital. Int $\mathrm{J}$ Contemp Pediatr. 2016; 3:253-255.

https://doi.org/10.18203/2349-3291.ijcp20160170

14. Ahmadpour KM, Zahedpasha $Y$, Taghavi M and Bijani A. Effect of phototherapy on platelet, reticulocyte and white blood cells in full term neonates with hyperbilirubinemia. Med $\mathrm{J}$ of Mashhad University of Medical Sciences. Wnter. 2013;55(4):211-217.

15. Monsef $A$ and Eghbalian $F$. Does conventional phototherapy have any effect on platelet count in full term neonates with indirect hyperbilirubinemia?. Health. 2011;3(12):709-711. https://doi.org/10.4236/health.2011.312119

16. Sakha $\mathrm{K}$ and Sultani $\mathrm{H}$. Effect of phototherapy on platelet and white blood cell count in term infants. Med J of Tabriz University of Medical Sciences. 2006;28(3):1418.

17. Modanlou HD, Oritz $\mathrm{O}$ and Wu PK. Lack of thrombocytopenia in newborn infants treated with phototherapy. Pediatric Research.1977; 11:538. https://doi.org/10.1203/00006450-197704000-01009

18. Abdul Tawab CN, Prakash RM Saldanha and Mithun HK. Phototherapy Induced Thrombocytopenia -A Comparative Study among Breastfed Term and Preterm Neonates With Hyperbilirubinemia. Int J Med Health Sci.2014;3(4):256-260.

\section{Author's contribution:}

SKS- Concept and manuscript writing; BB-Critical revision; SL, MM- Manuscript editing; NS, JA, V, KA, VK, AA, DG, TM- Review of literature; PB, SM-Compilation of records.

Work attributed to:

Department of Pediatric Medicine, Burdwan Medical College, Burdwan, West Bengal, India.

Orcid ID:

Dr. Biswajit Biswas - (i) https://orcid.org/0000-0002-9179-3098

Source of Funding: Nil, Conflict of Interest: None 